\title{
Identification and classification of the formation of intermediate ions measured in boreal forest
}

\author{
A. Hirsikko ${ }^{1}$, T. Bergman ${ }^{1}$, L. Laakso ${ }^{1}$, M. Dal Maso ${ }^{1}$, I. Riipinen ${ }^{1}$, U. Hõrrak ${ }^{1,2}$, and M. Kulmala ${ }^{1}$ \\ ${ }^{1}$ Department of Physical Sciences, University of Helsinki, P.O. Box 64, 00014 University of Helsinki, Finland \\ ${ }^{2}$ Institute of Environmental Physics, University of Tartu, Ülikooli 18, 50090 Tartu, Estonia
}

Received: 15 August 2006 - Published in Atmos. Chem. Phys. Discuss.: 25 September 2006

Revised: 14 December 2006 - Accepted: 8 January 2007 - Published: 15 January 2007

\begin{abstract}
We have measured the size distributions of air ions $(0.42-7.5 \mathrm{~nm}$ in diameter) with the Balanced Scanning Mobility Analyzer in boreal forest, in Southern Finland since spring 2003. The size range covers the size range of cluster ions (approximately $0.42-1.6 \mathrm{~nm}$ ) and naturally charged nanometre aerosol particles $(1.6-7.5 \mathrm{~nm})$ or intermediate air ions. Based on the measurements from April 2003 to March 2006 we studied the characteristics of charged aerosol particle formation by classifying each day either as a particle formation event, undefined or non-event day. The principal of the classification, as well as the statistical description of the charged aerosol particle formation events are given. We found in total 270 (26\% of the analysed days) and 226 (22\% of the analysed days) particle formation days for negative and positive intermediate ions, respectively. For negatively charged particles we classified 411 (40\% of the analysed days) undefined and 348 (34\% of the analysed days) nonevent days whereas for positively charged particles 343 (33\% of the analysed days) undefined and 460 (45\% of the analysed days) non-event days. The results were compared with the ordinary classification based on the Differential Mobility Particle Sizer (DMPS) measurements carried out at the same place. The above-presented values differed slightly from that found from the DMPS data, with a lower particle diameter of $3 \mathrm{~nm}$. In addition, we have found the rain-induced intermediate ion bursts frequently. The rain effect was detected on 163 days by means of negative ions and on 105 days by positive ones. Another interesting phenomenon among the charged aerosol particles was the appearance and existence of intermediate ions during the snowfall. We observed this phenomenon 24 times with negatively charged particles and 21 times with positively charged ones during winter months (October-April). These intermediate air ions were seen during the snowfall and may be caused by ice crystals, although the origin of these intermediate ions is unclear at the moment.
\end{abstract}

Correspondence to: A. Hirsikko

(anne.hirsikko@helsinki.fi)

\section{Introduction}

Aerosol particles in the atmosphere, both the primary and secondary, influence our lives in various ways. Depending on the chemical composition many aerosol particles are thought to be harmful to people's health (e.g. Pope et al., 2002). In addition to health effects the particles affect for example the Earth's radiation balance, cloud dynamics and precipitation (Kaufman et al., 2002). For these reasons especially the formation and growth of secondary aerosol particles have recently been under intensive research (e.g. Kulmala et al., 2004b).

Dal Maso et al. (2005) have analysed eight years of the particle size distributions measured with the Differential Mobility Particle Sizer (DMPS) at the SMEAR II station in Finland. They presented a detailed visual method for the distinction of the particle formation days from the days when there was no particle formation or generated new particles did not form a growing nucleation mode. The classification of days and observed new particle formation events enables us to further study the various properties of the forming secondary aerosol particles. Important properties to investigate are, for instance, the formation and growth rates of the particles and chemical compounds associated in these processes (e.g. Boy et al., 2005; Dal Maso et al., 2005).

Aerosol particles can be either neutral or charged. In fair weather conditions the charge on the aerosol particles originates mainly from cluster ions: either the cluster ions have grown to intermediate ion size class by ion-induced formation mechanisms or have attached to neutral aerosol particles (Israel, 1970). The charge is known to enhance the nucleation and condensation of the vapour molecules on clusters (Yu and Turgo, 2000; Laakso et al., 2003b; Nadykto and Yu, 2003; Wilhelm et al., 2004). We have noticed that sometimes particle formation is observed only with the DMPS but not with the Balanced Scanning Mobility Analyzer (BSMA, manufactured by Airel Ltd., Estonia, see Tammet, 2004, 2006), which measures naturally charged aerosol particles smaller than $7.5 \mathrm{~nm}$. On some other days the situation has

Published by Copernicus GmbH on behalf of the European Geosciences Union. 
been opposite and we have observed particle formation with the BSMA but not with the DMPS. However, all the intermediate ion formation events have not been observed in both charge polarities. All the phenomena related to air ions are not well known or even discovered at the moment. We have noticed some interesting changes in the particle size distributions when measuring with the ion spectrometers at different sites for example during rain and snowfall.

In this paper we introduce for the first time criteria that can be used to classify the intermediate ion formation events. We have modified the classification criteria given by Dal Maso et al. (2005) and analysed three years of charged particle data measured with the BSMA during April 2003-March 2006. We also were interested in finding the effect of different phenomena (for example rain and snowfall) on the mobility distributions of intermediate ions and finding the frequency of the influence of such effects. Here we will present the classification guidelines, the results of our analysis and compare them with the DMPS statistics, which have partly been published by Dal Maso et al. (2005).

\section{Measurements and methods}

In this study we utilised particle mobility and size distributions measured with the Balanced Scanning Mobility Analyzer (BSMA, manufactured by Airel Ltd., Estonia, Tammet, 2004, 2006) and the Differential Mobility Particle Sizer (DMPS) (Aalto et al., 2001). With the BSMA we obtained charged particle size distributions in the size range $0.42-$ $7.5 \mathrm{~nm}$ and with the DMPS we measured the size distributions of the charged and neutral particles starting at $3 \mathrm{~nm}$.

We have been measuring particle size distributions with the BSMA at Hyytiälä measurement station $\left(61^{\circ} 51^{\prime} \mathrm{N}\right.$, $24^{\circ} 17^{\prime} \mathrm{E}, 181 \mathrm{~m}$ above sea level) in Southern Finland since March 2003, with the exception of two longer service breaks (about one month). The DMPS has been measuring continuously at Hyytiälä since January 1996. Both the BSMA and DMPS sampled air inside the forest. The inlet for the BSMA has been approximately $2 \mathrm{~m}$ above the ground. The DMPS inlet has been at $2 \mathrm{~m}$ height until the end of September 2004, after which it was moved at about $8 \mathrm{~m}$ height. The BSMA and DMPS were placed in different measurement cabins less than $100 \mathrm{~m}$ away from each other. The measuring site and the permanent instrumentation of the station are described in more detail by Vesala et al. (1998), Kulmala et al. (2001), and Hari and Kulmala (2005).

\subsection{BSMA}

The BSMA (Balanced Scanning Mobility Analyzer) is an instrument developed to measure the mobility distributions of small air ions and naturally charged nanometre particles (intermediate ions) (http://www.airel.ee/). Tammet (2004, 2006) has described the BSMA in detail; here we give only a short introduction to the instrument. The device scans the mobility distributions of air ions and measures the natural air ion concentration of one polarity at a time with a plain typedifferential mobility analyser. The instrument consists of two mobility analysers (one for positive ions and the second for negative ions) and a common electrical amplifier, which are connected as a balanced bridge circuit. Inside each analyser there is one collecting element connected to common electrometer to measure the electrical current of air ions.

Sheath air is produced at the inlets of the analysers with the electro-filters (plates connected either to the ground or high voltage). The plates form an inlet gate for the air ions. The middle part of the inlet gate is electronically controlled: the gate is closed or opened for the ions depending on the measuring cycle of the instrument. The BSMA measures sample air (inlet gate opened) and the offset level of the measuring electrometer (inlet gate closed). Measuring algorithm calculates the mobility distributions based on the sample air measurements and error in the distributions based on the offset level measurements. The air flow of the BSMA is high, $221 \mathrm{~s}^{-1}$ per analyser, to suppress the losses of the smallest air ions.

The measuring cycle of the BSMA was three minutes per polarity until 15 August 2005. During the three minutes five sample and four offset scans were performed. The BSMA measured first the ions of one polarity and then the other polarity, for example first positive particles then negative ones. From the mid August 2005 the BSMA has been measuring in ten-minute-cycles where offset-level, positive and negative ion mobility distributions are scanned in turns (see Tammet, 2006).

The measuring range of the BSMA is 3.2$0.032 \mathrm{~cm}^{2} \mathrm{~V}^{-1} \mathrm{~s}^{-1}$ and mobility distributions are obtained in 16 fractions. The corresponding size distributions, which we utilised here, were calculated for 10 fractions in the diameter range of $0.42-7.5 \mathrm{~nm}$. In the size distribution calculations the limiting diameters for each fraction were constant and corresponding (temperature and pressure dependent) mobilities were calculated with the algorithm described by Tammet $(1995,1998)$ for each distribution. To reduce the temporal fluctuation of the data the three-minute data was averaged over $15 \mathrm{~min}$, whereas the ten-minute data was not further averaged. According to the manufacturer the concentration range of the BSMA is $0-40000 \mathrm{~cm}^{-3}$ for each mobility fraction, with the uncertainty of \pm 10 ions $\mathrm{cm}^{-3}$.

\subsection{DMPS}

We have measured aerosol particle size distributions with the DMPS-setup described by Aalto et al. (2001). Here we give only a summary of the utilised DMPS-instrumentation. The setup consists of two different DMPS-units, which have different but partly overlapping measuring ranges. The first DMPS consists of 10.9-cm long Hauke-type differential mobility analyzer (DMA) and TSI 3025 condensation particle 
counter (CPC). The second setup is composed of $28-\mathrm{cm}$ long DMA and TSI 3010 CPC. Aerosol is charged with $2 \mathrm{nCi}$ Krypton- 85 beta source before it is carried into the DMAs.

\section{Criteria for the classification of the formation of in- termediate air ions}

Traditionally molecular ions and small charged particles, in practise all charged particles that are smaller than about $1.6 \mathrm{~nm}$ in diameter, are called cluster ions (Hõrak et al., 1994, 2003). However, this border is rather conventional and we have observed that the maximum cluster size can vary between 1.2 and $2.0 \mathrm{~nm}$ depending on the season, time of day and charge polarity of ions. Charged particles with the diameter between that of clusters and $7.5 \mathrm{~nm}$ are called intermediate ions (Hõrrak et al., 2003). In fair weather conditions, the intermediate air ions are either formed via ion-induced formation mechanisms or the cluster ions have attached on the neutrally nucleated particles.

One of the objectives of the present paper is to identify the formation days of intermediate air ions and distinguish those days from unclear and non-event days. The criteria for the classification of the charged particle size distribution data follow the guidelines described by Dal Maso et al. (2005) for the DMPS system. However, due to the nature of air ions (clusters and naturally charged particles) and the measuring range of the BSMA we cannot directly adopt the criteria of Dal Maso et al. (2005). Although the BSMA cannot measure particles with the diameters larger than $7.5 \mathrm{~nm}$, we obtain the size distributions down to molecular sizes, which enable us to identify also the particle formation events that were suppressed at very small sizes, like at $3-5 \mathrm{~nm}$. These events cannot typically be detected with the DMPS (lower limit $3 \mathrm{~nm}$ ) or only few particles that have grown to $5 \mathrm{~nm}$ have been observed with the DMPS.

According to new classification criteria, the intermediate air ion formation events (hereinafter shortly called events) were divided into two main classes I and II. A detailed description of these classes and subclasses is given in Table 1 and Fig. 1. In the first class we have the most representative events that we should be able to utilise when studying various event characteristics, like particle concentrations and growth rates in small size fractions during the event. The less representative events, those which we will have difficulties to analyse further, belong into the class II.

The class I was further divided into three subclasses (Ia, Ib.1 and Ib.2), whereas Dal Maso et al. (2005) utilised only two subclasses Ia and Ib. The class-Ia events are the most representative event days, e.g. particularly suitable for case studies. The particles grow from cluster sizes over the measuring range of the BSMA and the number concentration of the particles in the new mode is typically high. The class$\mathrm{Ib}$ events either grow from the cluster sizes but the growth is suppressed at some size (subclass Ib.1) or there is a gap

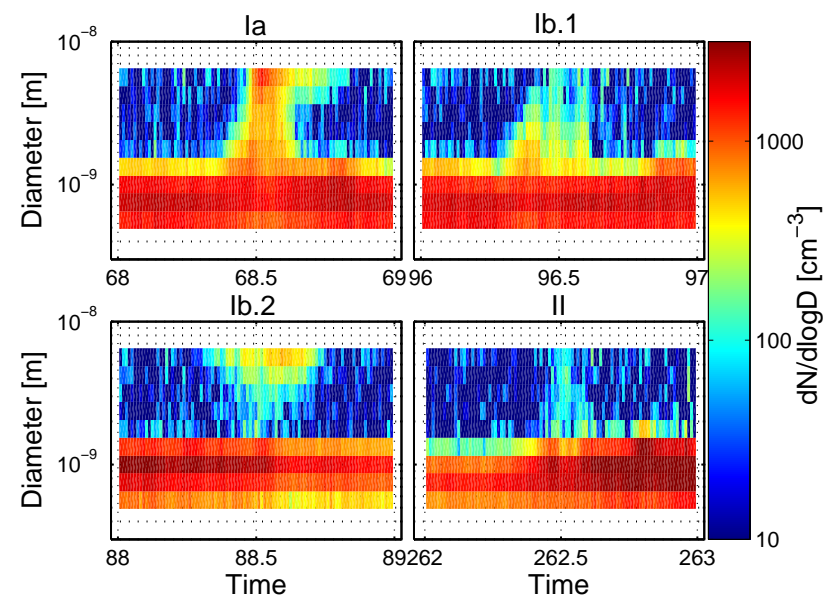

Fig. 1. The examples of the different types of intermediate ion formation events: The class Ia (top left panel), class Ib.1 (top right panel), class Ib.2 (bottom left panel) and class II (bottom right panel).

in the size distribution between cluster and intermediate ions during the event but the particles grow over the BSMA range (subclass Ib.2).

We wanted to distinguish the class I events for the purposes of later particle formation mechanism study. We believe that the ion-induced particle formation mechanism modified to some extend the intermediate ion concentrations during the class Ia and Ib.1 events. However, it is impossible to evaluate the relative contribution of ion-induced and neutral particle formation mechanisms by visually studying the size distributions. Furthermore, we suppose that the gap in the size distribution (class Ib.2) is an indication of the dominance of the neutral formation mechanisms of particles contrary to ion-induced formation mechanisms, when the gap in ion mobility/size distribution is filled by ions. It is also possible that the gap is due to the particles nucleated via neutral or ion-induced mechanism at some distance from the measurement site. These particles were slightly grown and charged by the attachment of cluster ions when they reached the measurement point. Thus, to draw more detailed conclusions about the particle formation mechanisms we need the exact calculations of the particle charging state based on the comparison of the data of different ion and particle measuring instruments (e.g. Laakso et al., 2006), and the estimations of neutral particle and ion nucleation rates. The events where the intermediate ion $(1.6-7.5 \mathrm{~nm})$ concentrations seemed to increase as a function of size but there was no gap in the distribution were not classified into class Ib. 2 but into class Ib. 1 or II.

We collected the different types of uncertain and unclear days to class called undefined days (Table 1 and Fig. 2). We detected frequently two interesting phenomena in the charged particle size distributions: rain-induced intermediate 
Table 1. The classification of different intermediate ion formation events/non-events based on the BSMA data.

\begin{tabular}{ll}
\hline Class $\quad$ Description \\
\hline Ia & - The formation of particles and subsequent evolution towards large sizes continued for several hours and \\
& the events had a clear continuous shape (Fig. 1), which indicates the homogeneity of the studied air mass \\
& during several hours. \\
- & The growth of new particles was clearly seen in the size distribution data. We are able to utilise these \\
& events when analysing, for example the growth rates of particles or other parameters that characterize the \\
& event. \\
- & The particles grew from cluster sizes up to 7.5 nm and henceforth probably over the measuring range of \\
& the BSMA. The number concentration of the particles in growing mode was high (Fig. 1).
\end{tabular}

$\mathrm{Ib}$

- The formation of new particles continued for several hours and the events had a clear shape (Fig. 1).

- The growth of particles was clearly seen, and we are typically able to utilise these events when analysing the event characteristics.

Ib. 1

- These events were not typically as strong (lower concentration) as class-Ia events and

- Sometimes the growth of new intermediate ions was suppressed.

Ib. 2

- The particle formation events of charged particles did not start from cluster ion mode and we saw a clear gap (not a single particle) in the ion distribution between the cluster and the intermediate ion modes.

II

- During these events the intermediate ion concentrations were sometimes too low for future analysis (Fig. 1).

- Many of the class-II events also had a difficult and unclear shape of growing mode that complicates their further study and the growth rate is obtainable only for some of these events.

- We saw a clear event. However, the BSMA was not measuring at some point during the event.

Undefined

- Extremely low concentration of the intermediate ions caused problems to define whether an event occurred or not (Fig. 2).

- Rain-induced intermediate ion burst and intermediate ions associated to snowfall are two interesting phenomena that are seen only among the charged particles (Fig. 2). Both the rain-induced ions and snowfall associated intermediate ions can occur during the particle formation days, which is why we counted the total number of days when they occurred.

- Sometimes the noise of measuring electrometers (unbalance of the instrument) disturbed the size distributions and we could not identify whether some real particles were measured or not (Fig. 2).

Non-event

- We did not observe charged particles larger than cluster ions (above $1.8 \mathrm{~nm}$ ) (Fig. 3).

ion bursts (Hõrrak et al., 2005) and the existence of intermediate ions during snowfall. The rain-induced ion bursts are associated with the breaking of the water droplets into small negative droplets and one large positive droplet. There are couple of mechanisms that could cause the phenomenon.
Firstly, subsequent consecutive Rayleigh explosion and the evaporation of charged water droplets can result in the formation of particles in the intermediate air ion range (GameroCastaño and Fernández de la Mora, 2000a, b). Secondly, the charged nanometre particles could form by ion evaporation 


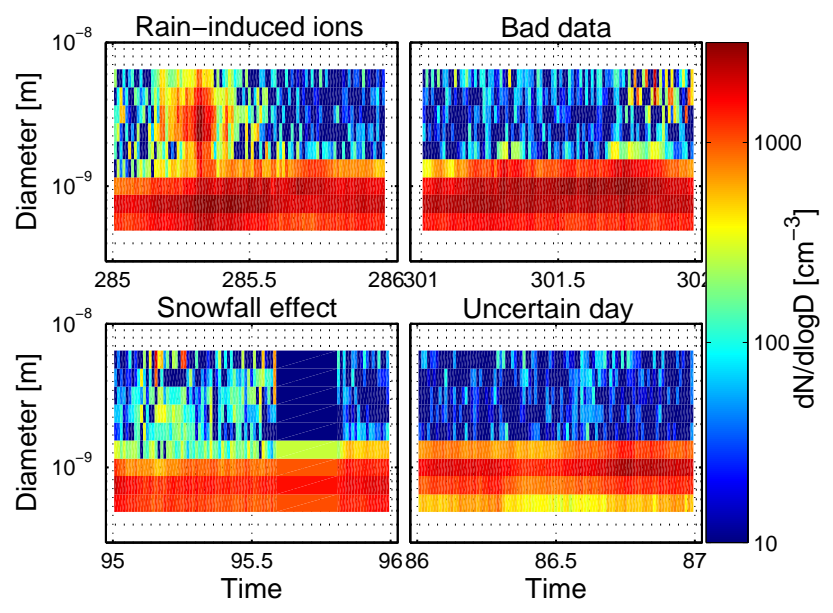

Fig. 2. The examples of undefined days: rain induced intermediate ions (top left panel), the bad data: the concentration of intermediate air ions increased due to the instrumental noise of the BSMA (top right panel), intermediate ions associated to snowfall (bottom left panel) and unclear case, when whether a very weak event was detected in the afternoon or not (bottom right panel).

from charged raindrops by the breaking or splashing of raindrops (Iribarne and Thomson, 1976). Due to the formation mechanisms of the rain-induced intermediate ions they could be multiple charged and particles with various sizes can have same mobilities and, therefore, contribute to the concentration of intermediate ions. However, the formation mechanisms of the charged particles during rain are not well known and understood.

The intermediate ions were sometimes observed during the snowfall. On one hand the intermediate ions were not observed to form a growing mode during the snowfall, as in the case of rain-induced intermediate ion bursts. On the other hand, the cause or formation mechanisms of this phenomenon are not known and are not discussed here in detail. We have to note that the data of the BSMA was not typically stable during snowfall phenomenon and it may be difficult to study the phenomenon based on the BSMA data. However, each intermediate ion phenomenon associated to snowfall was also observed with another kind of air ion spectrometer (AIS, Airel Ltd., see for example Laakso et al., 2004) which data was always stable during the snowfall. Non-event days were such days when the cluster ions were the only particles that we observed in considerable concentrations by the BSMA (Fig. 3).

\section{Results}

Our main focus in this study was to identify and separate the intermediate air ion formation event days from the other days. The results of the analysis are introduced below and compared with the corresponding DMPS-findings. Statistics

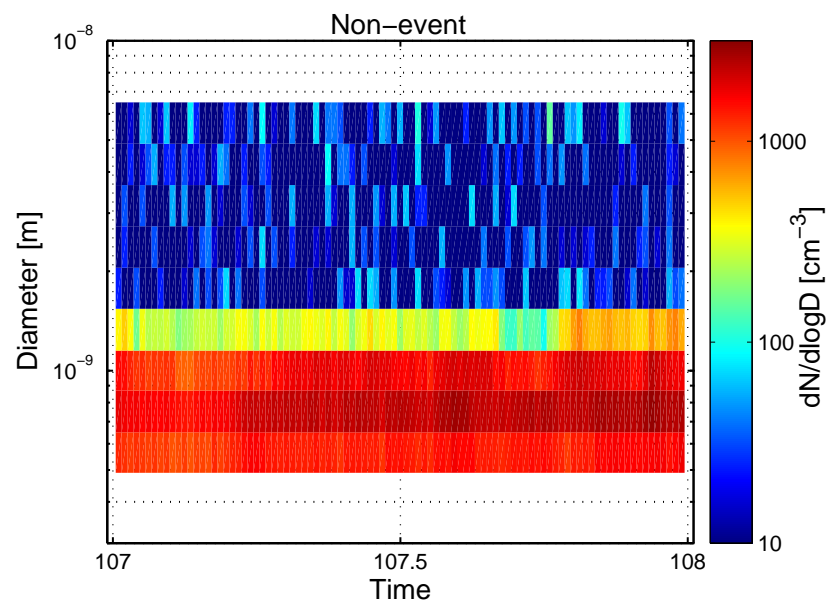

Fig. 3. An example of non-event day.

for the further classification of charged particle events are also discussed. Finally we report the frequency of the raininduced ion bursts and the snowfall associated intermediate ion phenomenon.

Periods with at least one day gap in either the DMPS or BSMA data were excluded from the analysis to make the statistics of event, undefined and non-event days comparable with each other. The longest measurement breaks with the BSMA were during August 2003 and March 2004. The DMPS had only single day breaks in measurements. The measurement period was from April 2003 to March 2006, therefore each year begins from the beginning of April and ends at the end of March in our below analysis. We had 321, 358 and 350 days to study for the first, second and third year, respectively.

\subsection{Event classification statistics: BSMA vs. DMPS}

The main results of the analysis are collected to the Table 2 . The number of event, undefined and non-event days of positive and negative as well as the whole aerosol population (charged and neutral) varied from year to year. The number of available days in the analysis was slightly different in each year. For that reason it is more illustrative to investigate the relative occurrence (the percentage of analysed days) of the different types of days when comparing the differences between studied years and various instruments. The trend in the relative appearance of event, undefined and non-event days was similar for positive and negative intermediate ions. The relative appearance of the particle formation events days turned out to be with small changes nearly the same from year to year for both polarities, and the maximum was during the second year (April 2004-March 2005). The appearance of undefined and non-event days varied from year to year for both polarities more than the corresponding statistics for particle formation events. The DMPS data displayed 
Table 2. Comparison between the total numbers of particle formation event, undefined and non-event days measured with the BSMA and DMPS during three years (April 2003-March 2006). The fifth column presents the number of days when both the DMPS and BSMA (either positive or negative polarity) showed event, undefined or non-event on the same day. Each year begins from the beginning of April and ends at the end of March. The total number of analysed days was 321, 358 and 350 for the first, second and third year, respectively. The percentage of event, undefined and non-event days from the analysed (i.e. event + undefined + non-event days) days is presented in parentheses.

\begin{tabular}{lllll}
\hline Year & BSMA+ & BSMA- & DMPS & DMPS and BSMA \\
\hline Event days & & & & \\
1 April 2003-31 March 2004 & $68(21)$ & $76(24)$ & $102(32)$ & $74(23)$ \\
1 April 2004-31 March 2005 & $88(24)$ & $102(28)$ & $111(31)$ & $95(27)$ \\
1 April 2005-31 March 2006 & $70(20)$ & $92(26)$ & $73(21)$ & $60(17)$ \\
\hline Undefined days & & & & \\
1 April 2003-31 March 2004 & $92(29)$ & $118(37)$ & $140(43)$ & $67(21)$ \\
1 April 2004-31 March 2005 & $128(36)$ & $155(43)$ & $144(40)$ & $100(28)$ \\
1 April 2005-31 March 2006 & $123(35)$ & $138(40)$ & $165(47)$ & $93(27)$ \\
\hline Non-event days & & & & \\
1 April 2003-31 March 2004 & $161(50)$ & $127(39)$ & $79(25)$ & $55(17)$ \\
1 April 2004-31 March 2005 & $142(40)$ & $101(29)$ & $103(29)$ & $72(20)$ \\
1 April 2005-31 March 2006 & $157(45)$ & $120(34)$ & $112(32)$ & $74(21)$ \\
\hline
\end{tabular}

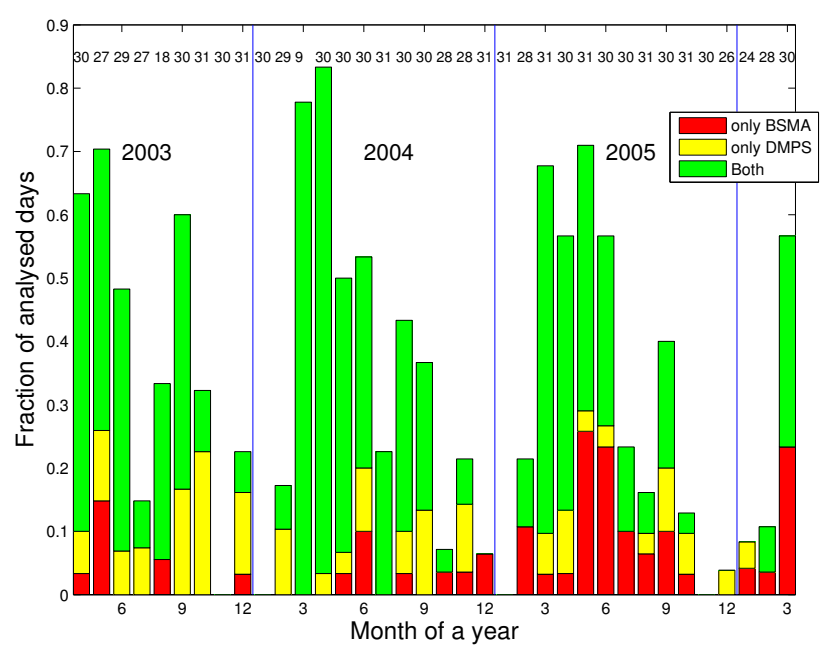

Fig. 4. Monthly differences in the occurrence of simultaneous and non-simultaneous particle formation events (the number of events per analysed days in each month) based on the BSMA and DMPS measurements. Red colour indicates the fraction of days when only the BSMA measured intermediate ion (either positive or negative) formation, yellow colour indicates the fraction of days when only the DMPS measured particle formation. Green colour presents the fraction of days when both the BSMA and DMPS measured particle formation. The number of analysed days in each month is given in the upper part of the figure.

the decrease in the relative appearance of events each year, while the relative occurrence of non-event days increased.

We observed more particle formation events with the DMPS than with the BSMA when comparing differences es- pecially during the first two years (Table 2 and Fig. 4). Based on the DMPS measurements some of the events become obvious at sizes (see Dal Maso et al., 2005) which are out of the BSMA's measuring range and these events cannot be detected with the BSMA. On such days the particle formation has most likely occurred away from the measuring station and the particles that travelled with air masses had already grown. However, in 2005 and 2006 the number of event days based on the DMPS measurements was smaller compared to the negatively charged particles. When comparing polarity differences, we observed more charged particle events and undefined days among the negatively charged particles than positively charged ones. Differences in the event rates of positive and negative ions indicate the importance of charge polarity in the particle formation, i.e. negatively charged particles seemed sometimes to be involved in the particle formation more favourably (see for example Froyd and Lovejoy, 2003a, b; Lovejoy et al., 2004). The difference in the number of undefined days is partly explained by the different occurrence rates of rain-induced intermediate ion bursts (see more detailed description below).

We have found that the annual cycle of the charged particle events detected by the BSMA followed the corresponding cycle based on the DMPS measurements with the exception of a couple of months (Table 2 and Fig. 4). Most of the events were detected between spring and autumn. The annual maximum for the non-event days occurred during winter time by both instruments. Dal Maso et al. (2005) had also observed that particle formation days are typically rare in boreal forest during winter. We observed a clear maximum of undefined days for charged particles between June and September, with an exception of the year 2003 when any clear maximum was 
Table 3. Statistics for positively and negatively charged particle formation events during April 2003-March 2006. Each year begins from the beginning of April and ends at the end of March. Both the total number of the different types of events during three years and the annual number of these events are presented. The fourth column presents the number of days when the events of both polarities were in the same subclass. In parentheses the percentage from the classified days (i.e. events + non-events) is indicated. The percentages are calculated for the total number of events from the total classified days, whereas for the annual number of events from the corresponding classified days.

\begin{tabular}{llll}
\hline Event class & BSMA+ & BSMA- & Both in same class \\
\hline Ia in total & $31(5)$ & $69(11)$ & 29 \\
1 April 2003-31 March 2004 & $8(3)$ & $19(9)$ & 8 \\
1 April 2004-31 March 2005 & $17(7)$ & $36(18)$ & 15 \\
1 April 2005-31 March 2006 & $6(3)$ & $14(7)$ & 6 \\
\hline Ib in total & $89(13)$ & $94(15)$ & 37 \\
1 April 2003-31 March 2004 & $26(11)$ & $20(10)$ & 9 \\
1 April 2004-31 March 2005 & $37(16)$ & $33(16)$ & 12 \\
1 April 2005-31 March 2006 & $26(11)$ & $41(19)$ & 16 \\
\hline Ib.1 in total & $70(10)$ & $88(14)$ & 37 \\
\hline Ib.2 in total & $19(3)$ & $6(1)$ & 0 \\
\hline II in total & $106(15)$ & $107(17)$ & 59 \\
1 April 2003-31 March 2004 & $34(15)$ & $37(18)$ & 21 \\
1 April 2004-31 March 2005 & $34(15)$ & $33(16)$ & 18 \\
1 April 2005-31 March 2006 & $38(17)$ & $37(17)$ & 20 \\
\hline Events in total & $226(33)$ & $270(44)$ & 125 \\
\hline
\end{tabular}

not seen. The summer maximum of undefined days is caused mainly by rain-induced ion bursts and to some extent by operational ability of the BSMA, i.e. the measurement uncertainty increases significantly in the case of high relative humidity and the dirty insulators (by pollen etc.) of the mobility analyser. For the DMPS data undefined days were more evenly distributed through the year.

What are the other reasons that caused the differences in the numbers of events between positive and negative intermediate ions and the whole aerosol population (charged and neutral particles)? Firstly, some of the charged particle events, especially in winter (in February and March of 2005 and 2006), were suppressed at sizes of $3-5 \mathrm{~nm}$ and could not be detected with the DMPS because of the low steadystate charging probability of nanometre particles. We observed such days 21 times among negative ions and 6 times among positive ones. The demise of the particle formation event was probably due to the low concentration of condensing vapours (e.g. $\mathrm{H}_{2} \mathrm{SO}_{4}$ and organics) or rapid increase of condensation sink. Secondly, we have recently observed the relationship between particle formation mechanisms, neutral or ion-induced, to vary from day to day, which affects the amount of intermediate ions during particle formation (for example Laakso et al., 2006). The differences between positive and negative intermediate ions indicate that conditions that led to the particle formation in Hyytiälä sometimes favoured the negatively charged particles (see also the next section). However, we observed positive ion forma- tion events frequently, which indicate that their formation was also important. Thirdly, sometimes the resolution of the BSMA and the quality of the data led us to classify some of the days as undefined days. Only in the class II we may have some questionable events since sometimes the low concentration of charged particles may have caused misjudgement.

\subsection{Differences between charge polarities}

We have found two main differences when classifying the charged particle formation events (Table 3 ). Firstly, the classIa events were more frequent among the negative intermediate ions. Secondly, the class-Ib.2 events were found to be more common among the positive intermediate ions than for the negative ones. However, the class-Ib.2 days were altogether rare. The main reason for having only a few class-Ib. 2 events is that we wanted to identify the days with a clear gap (concentration of $\sim 0 \mathrm{~cm}^{-3}$ ) between clusters and new intermediate ion mode. The relative appearance of the class-II events of all classified days (event + non-event days) showed only a minor variation from year to year for both polarities (see Table 3). On the contrast, the relative appearance of class Ia and Ib events for positively charged particles was significantly higher during the second year (April 2004-March 2005) than during the first or third years, whereas for negatively charged particles also during the third year the relative occurrence of the class-Ib events was significantly higher than during the first year. 
Table 4. The number of the days of two special phenomena: raininduced ion bursts and snowfall associated intermediate ion phenomenon. The statistics for the rain-induced bursts are only for periods April-October.

\begin{tabular}{lll}
\hline Year & BSMA + & BSMA - \\
\hline Rain-induced ion burst, total & 105 & 163 \\
1 April 2003-31 Oct 2003 & 27 & 46 \\
1 April 2004-31 Oct 2004 & 47 & 71 \\
1 April 2005-31 Oct 2005 & 31 & 46 \\
\hline Snowfall effect, total & 21 & 24 \\
1 April 2003-31 March 2004 & 9 & 10 \\
1 April 2004-31 March 2005 & 10 & 12 \\
1 April 2005-31 March 2006 & 2 & 2 \\
\hline
\end{tabular}

Typically the negatively charged particle formation events had the same or higher rank than corresponding events for positively charged particles on the same day. We found only a couple of exceptions. Some indication of these observations can be seen on the Table 3. These observations support the fact that the environmental conditions at Hyytiälä SMEAR station were sometimes more favourable for the negatively charged particle formation.

\subsection{Rain and snowfall associated intermediate air ions}

Two special phenomena found among charged particles were rain and snowfall associated intermediate ion bursts (see Fig. 2). When identifying the rain-induced ion bursts, we utilised information about precipitation measured with ARG-100 tipping bucket counter (Vector Instruments, Rhyl, Clwyd, UK, Laakso et al., 2003a) between the beginning of April and the end of October. During the other months there was a high probability for the water measuring instrument to be frozen.

We observed rain-induced ion bursts among negative and positive intermediate ions on 163 and 105 days, respectively (Table 4 and Fig. 5). Depending on the raining conditions these bursts could be detected many times a day, even on the same day as particle formation was observed. During the three studied summers the highest monthly number of days when the rain-induced ion bursts were observed was in June for the ions of both polarities, although the rate of raininduced ion bursts depends on the amount and type of rain. We observed some (in total 11 and 42 with the positive and negative ions, respectively) rain-induced ion bursts also in each winter (November-February). However, they were left out from the Table 4 and Fig. 5, because we could not detect the raining reliably in winter.

We detected the intermediate ions associated to the snowfall in the negative and positive intermediate ion distributions on 24 and 21 days, respectively (Table 4 and Fig. 5). This
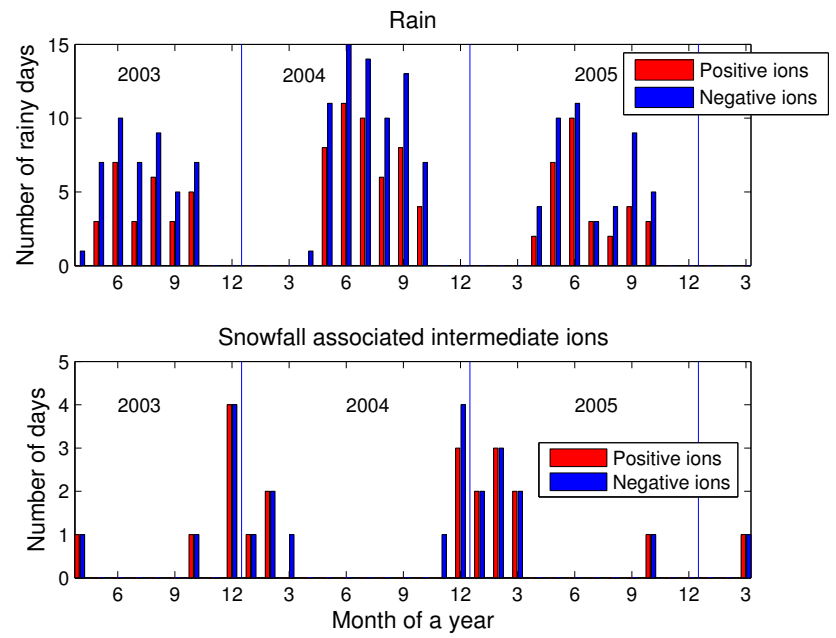

Fig. 5. The annual rate of days when rain-induced ion bursts (top panel) and intermediate ions during snowfall (bottom panel) were observed.

phenomenon was observed in winter months, between October and April. In December 2003 and 2004 we saw the phenomenon four times among negative intermediate ions, which was the maximum number during one month. For positive ions the corresponding maximum appearance rate was four per month also in December 2003. We observed both the rain-induced intermediate ion bursts and the effect of snowfall either with both polarities or only in the negative intermediate ion size distributions.

We observed the intermediate ions during the snowfall and believe that they could be caused by snowflake or hail originated particles and/or ice crystals. More information about the origin of these intermediate ions can be obtained by studying simultaneous measurements of ion size distributions and meteorological parameters like the type of snowfall together with theoretical approach.

\section{Summary and conclusions}

We analysed three years (from April 2003 to March 2006) of naturally charged particle size distributions measured with the BSMA in Hyytiälä, in order to identify the formation events of intermediate air ions. The particle formation event classification guidelines for the DMPS data proposed by Dal Maso et al. (2005) inspired us to classify the charged particle events in a similar manner to the different classes; on one hand to distinguish between particle formation event days from non-event days and on the other hand the days with special characteristics.

We observed the differences in the frequency of particle formation events between positively and negatively charged particles measured by the BSMA and the whole aerosol population (charged and neutral) measured by the DMPS, which 
confirmed our preliminary observations. In general, the percentage of particle formation event days per year during the three studied years was nearly constant: about $20-24 \%$ and 24-28\% based on positive and negative ion measurements, respectively. However, the relative number of particle formation events detected with the DMPS has been decreasing from $32 \%$ down to $21 \%$ during the same period. In each studied year we observed the charged particle formation events during which the particle growth was stopped at small sizes (around 3-5 nm). These kinds of charged particle formation events were observed especially in February and March. The growth of the particles was thought to stop due to the low concentration of condensing vapours (e.g. $\mathrm{H}_{2} \mathrm{SO}_{4}$ and organics) or rapid increase of condensation sink. Thus, with ion spectrometers we obtain information about the initial steps of the particle formation and growth (see e.g. Kulmala et al., 2004a; Hirsikko et al., 2005).

In addition to differences in particle formation event rates between the charged particles and whole aerosol population (charged and neutral) we observed charge polarity differences. We found out that negatively charged particle formation events were typically more representative than the corresponding events for the positively charged particles. During the three years, we observed 270 negative intermediate ion formation events and 226 positive ion events, thus there were in total 44 negatively charged particle events more than positive ones. These results indicate that ambient conditions leading to particle formation sometimes favoured the negatively charged particles over the positive ones. Thus, charged particle measurements can give extra information about the charging state of nanometre particles during particle formation. This valuable information together with the DMPS measurements can be used to study the different particle formation mechanisms.

We observed frequently two interesting phenomena, raininduced intermediate ion bursts and intermediate ions during the snowfall in our study. Hõrrak et al. $(2005,2006)$ have studied the formation of rain-induced intermediate ion bursts both in laboratory and in nature. The intermediate ions observed during the snowfall, however, need further analysis since their cause and the related ion formation mechanism are currently somewhat unclear.

Acknowledgements. A. Hirsikko would like to acknowledge Maj and Tor Nessling foundation for their financial support (grant 2006168). This work has in part been supported by Estonian Science foundation through grant 6223 . The authors thank P. Aalto for his work with the DMPS and the staff of SMEAR II station for maintaining the measurements. The authors would like to acknowledge also T. Tuomi for the discussion about ice electricity.

Edited by: M. Ammann

\section{References}

Aalto, P., Hämeri, K., Becker, E., Weber, R., Salm, J., Mäkelä, J. M., Hoell, C., O’Dowd, C. O., Karlsson, H., Hansson, H.-C., Väkevä, M., Koponen, I. K, Buzorius, G., and Kulmala, M.: Physical characterization of aerosol particles during nucleation events, Tellus, 53B, 344-358, 2001.

Boy, M., Kulmala, M., Ruuskanen, T. M., Pihlatie, M., Reissell, A., Aalto, P. P., Keronen, P., Dal Maso, M., Hellen, H., Hakola, H., Jansson, R., Hanke, M., and Arnold, F.: Sulphuric acid closure and contribution to nucleation mode particle growth, Atmos. Chem. Phys., 5, 863-878, 2005, http://www.atmos-chem-phys.net/5/863/2005/.

Dal Maso, M., Kulmala, M., Riipinen, I., Wagner, R., Hussein, T., Aalto, P. P., and Lehtinen, K. E. J.: Formation and growth of fresh atmospheric aerosols: eight years of aerosol size distribution data from SMEAR II, Hyytiälä, Finland, Boreal Environ. Res., 10, 323-336, 2005.

Froyd, K. D. and Lovejoy, E. R.: Experimental Thermodynamics of Cluster Ions Composed of $\mathrm{H}_{2} \mathrm{SO}_{4}$ and $\mathrm{H}_{2} \mathrm{O}$. 1. Positive Ions, J. Phys. Chem. A, 107, 9800-9811, 2003a.

Froyd, K. D. and Lovejoy, E. R.: Experimental Thermodynamics of Cluster Ions Composed of $\mathrm{H}_{2} \mathrm{SO}_{4}$ and $\mathrm{H}_{2} \mathrm{O}$. 2. Measurements and ab Initio Structures of Negative Ions, J. Phys. Chem. A, 107, 9812-9824, 2003b.

Gamero-Castaño, M. and Fernández de la Mora, J.: Direct measurement of ion evaporation kinetics from electrified liquid surfaces, J. Chem. Phys., 113, 815-832, 2000a.

Gamero-Castaño, M. and Fernández de la Mora, J.: Mechanisms of electrospray ionisation of singly and multiply charged salt clusters, Analytica Chimica Acta, 406, 67-91, 2000b.

Hari, P. and Kulmala, M.: Station for Measuring EcosystemAtmosphere Relations (SMEAR II), Boreal Environ. Res., 10, 315-322, 2005.

Hirsikko, A., Laakso, L., Hörrak, U., Aalto, P. P., Kerminen, V.M., and Kulmala, M.: Annual and size dependent variation of growth rates and ion concentrations in boreal forest, Boreal Environ. Res., 10, 357-369, 2005.

Hõrrak, U., Iber, H., Luts, A., Salm, J., and Tammet, H.: Mobility spectrum of air ions at Tahkuse Observatory, J. Geophys. Res., 99, $10697-10700,1994$.

Hõrrak, U., Salm, J., and Tammet, H.: Diurnal variation in the concentration of air ions of different mobility classes in a rural area J. Geophys. Res., 108, 4653, doi:10.1029/2002JD003240, 2003.

Hõrrak, U., Tammet, H., Aalto, P. P., Vana, M., Hirsikko, A., Laakso, L., and Kulmala, M.: Formation of charged nanometer aerosol particles associated with rainfall, Proceedings of European Aerosol Conference 2005, p. 606, 2005.

Hõrrak, U., Tammet, H., Aalto, P. P., Vana, M., Hirsikko, A., Laakso, L., and Kulmala, M.: Formation of Charged Nanometer Aerosol Particles Associated with Rainfall: Atmospheric Measurements and Lab Experiment, Proceedings of BACCI, NECC and FCoE activities 2005, Report Series in Aerosol Sciences, 81, 180-185, 2006.

Iribarne, J. V. and Thomson, B. A.: On the evaporation of small ions from charged droplets, J. Chem. Phys., 64, 2287-2294, 1976.

Israel, H.: Atmospheric electricity, Israel Program for Scientific Translations, 1, Jerusalem, 1970.

Kaufman, Y. J., Tanré, D., and Boucher, O.: A satellite view of aerosols in the climate system, Nature, 419, 215-223, 2002. 
Kulmala, M., Hämeri, K., Aalto, P. P., Mäkelä, J. M., Pirjola, L., Nilsson, E. D., Buzorius, G., Rannik, Ü., Dal Maso, M., Seidl, W., Hoffman, T., Janson, R., Hansson, H.-C., Viisanen, Y., Laaksonen, A., and O'Dowd, C. D.: Overview of the international project on biogenic aerosol formation in the boreal forest (BIOFOR), Tellus, 53B, 324-343, 2001.

Kulmala, M., Laakso, L., Lehtinen, K. E. J., Riipinen, I., Dal Maso, M., Anttila, T., Kerminen, V.-M., Hörrak, U., Vana, M., and Tammet, H.: Initial steps of aerosol growth, Atmos. Chem. Phys., 4, 2553-2560, 2004a.

Kulmala, M., Vehkamäki, H., Petäjä, T., Dal Maso, M., Lauri, A., Kerminen, V.-M., Birmili, W., and McMurry, P. H.: Formation and growth rates of ultrafine atmospheric particles: A review of observations, J. Aerosol Sci., 35, 143-176, 2004b.

Laakso, L., Grönholm, T., Rannik, Ü., Kosmale, M., Fiedler, V., Vehkamäki, H., and Kulmala, M.: Ultrafine particle scavenging coefficients calculated from 6 years field measurements, Atmos. Environ., 37(25), 3605-3613, 2003a.

Laakso, L., Kulmala, M., and Lehtinen K. E. J.: Effect of condensation rate enhancement factor on 3-nm (diameter) particle formation in binary ion-induced and homogeneous nucleation, J. Geophys. Res., 108, 4574, doi:10.1029/2003JD003432, 2003b.

Laakso, L., Anttila, T., Lehtinen, K. E. J., Aalto, P. P., Kulmala, M., Hõrrak, U., Paatero, J., Hanke, M., and Arnold, F.: Kinetic nucleation and ions in boreal particle formation events, Atmos. Chem. Phys., 4, 2353-2366, 2004, http://www.atmos-chem-phys.net/4/2353/2004/.

Laakso, L., Gagné, S., Petäjä, T., Hirsikko, A., Aalto, P., Kulmala, M., and Kerminen, V.-M.: Detecting charging state of ultra-fine particles: instrumental development and ambient measurements, Atmos. Chem. Phys. Discuss., 6, 6401-6429, 2006, http://www.atmos-chem-phys-discuss.net/6/6401/2006/.

Lovejoy, E. R., Curtius, J., and Froyd, K. D.: Atmospheric ioninduced nucleation of sulphuric acid and water, J. Geophys. Res., 109, D08204, doi:10.1029/2003JD004460, 2004.
Nadykto, A. and Yu, F.: Uptake of neutral polar vapour molecules by charged particles: Enhancement due to dipolecharge interaction, J. Geophys. Res., 108(D23), 4717, doi:10.1029/2003JD003664, 2003.

Pope, C. A., Burnett, R. T., Thun, M. J., Calle, E. E., Krewski, D., Ito, K., and Thurston, G. D.: Lung Cancer, Cardiopulmonary Mortality, and Long-term Exposure to Fine Particulate Air Pollution, J. Amer. Med. Assoc., 287, 1132-1141, 2002.

Tammet, H.: Size and mobility of nanometer particles, clusters and ions, J. Aerosol Sci., 26, 459-475, 1995.

Tammet, H.: Reduction of air ion mobility to standard conditions, J. Geophys. Res., 103, 13 933-13 937, 1998.

Tammet, H.: Balanced Scanning Mobility Analyzer, in: Proc. 16th International Conference on Nucleation \& Atmospheric Aerosols in Kyoto, 2004.

Tammet, H.: Continuous scanning of the mobility and size distribution of charged clusters and nanometer particles in atmospheric air and the Balanced Scanning Mobility Analyzer BSMA, Atmos. Res., 523-535, 2006.

Vesala, T., Haataja, J., Aalto, P., Altimir, N., Buzorius, G., Garam, E., Hämeri, K., Ilvesniemi, H., Jokinen, V., Keronen, P., Lahti, T., Markkanen, T., Mäkelä, J. M., Nikinmaa, E., Palmroth, S., Palva, L., Pohja, T., Pumpanen, J., Rannik, Ü., Siivola, E., Ylitalo, H., Hari, P., and Kulmala, M.: Long-term field measurements of atmosphere-surface interactions in boreal forest combining forest ecology, micrometeorology, aerosol physics and atmospheric chemistry, Trends in Heat, Mass and Momentum Transfer, 4, 17$35,1998$.

Wilhelm, S., Eichkorn, S., Wiedner, D., Pirjola, L., and Arnold, F.: Ion-induced aerosol formation: new insights from laboratory measurements of mixed cluster ions $\mathrm{HSO}_{4}{ }^{-}\left(\mathrm{H}_{2} \mathrm{SO}_{4}\right)_{a}\left(\mathrm{H}_{2} \mathrm{O}\right)_{w}$ and $\mathrm{H}^{+}\left(\mathrm{H}_{2} \mathrm{SO}_{4}\right)_{a}\left(\mathrm{H}_{2} \mathrm{O}\right)_{w}$, Atmos. Environ., 38, 1735-1744, 2004.

Yu, F. and Turco, R. P.: Ultrafine aerosol formation via ionmediated nucleation, Geophys. Res. Lett., 27(6), 883-886, 2000. 